\title{
Early Intervention of Kindergarten Children at Risk for Developmental Disabilities: A Greek Paradigm
}

\author{
Maria Tzouriadou ${ }^{1, *}$, Constantinos Vouyoukas ${ }^{1}$, Eleni Anagnostopoulou ${ }^{1}$ and \\ Lito E. Michalopoulou² \\ ${ }^{1}$ University of Thessaloniki, Faculty of Education, Educational Tower, University Campus, Thessaloniki \\ 54124, Greece \\ ${ }^{2}$ Pennsylvania State University, USA
}

\begin{abstract}
Internationally most of the children at risk for developmental disabilities (intellectual disabilities, learning disabilities and language impairments) are detected within preschool settings. In Greece there are no early intervention services mandated nationwide. In practice, not detailed guidance and support is given to preschool teachers regarding the assessment and intervention of children at risk. This study provides research evidence from the implementation of an early intervention program in inclusive kindergartens, which is part of the practical training of students from the Faculty of Preschool Education Sciences, Department of Psychology and Special Education, Aristotle University of Thessaloniki, Greece. Response to intervention, as applied to kindergartens, was used to detect children not responding to core kindergarten curriculum. An inclusive early intervention educational program was implemented based on children's profiles of strengths and weaknesses. At risk children participated in large group classroom activities with all children. For these children a specialized inclusive program with emphasis on school readiness was implemented. For children with developmental disabilities, an intensive individualized program was implemented, which put emphasis on the improvement of their cognitive abilities and socialization.
\end{abstract}

Keywords: Kindergarten, early intervention, inclusive curricula, developmental disabilities, at risk children, response to intervention, dynamic assessment.

\section{INTRODUCTION}

At risk children have an increased probability of a disability occurring, due to medically diagnosed conditions or syndromes, deprived environments which limit children's ability to profit from important learning experiences, or biological causes of prenatal, perinatal and neonatal factors. Children with developmental disabilities exhibit significant deviations from the normally expected pattern of development. These kinds of disabilities may express themselves in forms of delay and/or physical, cognitive and emotional dysfunction. On a basis of a transactional model of development, developmental disabilities are regarded as a dynamic process in which various factors are involved. Among these factors are gender, social class and culture. Thus, developmental delay may be spontaneously removed or compensated for [1].

Early intervention is intended for all at risk children and can offer support from prenatal diagnosis to the moment that the child reaches compulsory schooling. Considering that these children constitute a vulnerable group with special needs, early intervention was first initiated since 1964 by Head Start programs. Head Start programs promote school readiness, which

*Address correspondence to this author at the University of Thessaloniki, Faculty of Education, Educational Tower, University Campus, Thessaloniki 54124, Greece; Tel: +30 2310991299; E-mail: tzour@nured.auth.gr means that children are ready for school, families are ready to support their children's learning and schools are ready for children [2]. Data collected through the Head Start program during 1986 to 1990 indicated that the percentage of programs enrolling at least one child with disabilities increased from $37 \%$ to $74.2 \%$ [3]. Furthermore McDonnell, Brownell and Wolery [4] demonstrated a smaller percentage (56\%) in public kindergartens. Buscemi L, Bennett T, Thomas D, et al. [5], Barnett, Carey \& Hall [6] provided similar research findings.

Olness [7] reported that 780 million children from birth till 5 years of age may develop disabilities as a result of an increasing amount of established biological and environmental factors, which may serve as causes of these children at risk. Besides the increasing number of established genetic and neurological causes of developmental disabilities, other environmental conditions may lead to developmental disabilities, such as malnutrition, intoxication, birth underweight, malignancies etc. Possible environmental causes for developmental disabilities include poverty, abuse and child neglect. Park, Turnbull and Turnbull [8] argued that the environmental causes may operate independently or interactively with biological causes. Considering the dynamics of the causes and factors that may lead to developmental disabilities, it is not difficult to estimate the accumulative consequences that may affect child's cognitive growth al. [9]. 
Early educational intervention was established in the US with the Education of the Handicapped Act Amendments in 1986 [10]. According to this Act, infants and toddlers with disabilities are entitled to interdisciplinary assessment and intervention. This Act also specified parental and family rights within a framework of individualized family services. In this Act were different provisions and systems of support for children 3-5 years old, which put less emphasis on family participation, especially for preschool children. In the US different systems of early intervention were implemented. Despite this variation, all systems put emphasis on interdisciplinary assessment and the developmentally appropriate intervention. Guralnick [11] argues that the intervention aims were the maximization of children's participation in classroom activities, children's inclusion and the application of individualized intervention programs based on children needs, all of which within a systemic perspective [12].

Guralnick [13] and Shonkoff \& Hauser-Cram [14] provided research findings over the last 30 years indicating that the implementation of early intervention programs on at risk children and those with developmental disabilities up to 5 years of age reduces the disability symptoms. Bryant and Maxwell [15] and Martin, Ramey and Ramey [16] provided other research findings indicating that early educational interventions had temporary positive effects on children at risk (especially on children with intelligence quotient score $<70$ whose families had limited access to resources). It was found that lack of early educational intervention programs may lead to mental retardation either for at risk children or for children with established developmental disabilities.

After 1990 there was a gradual change of early intervention theoretical framework and implemented services. Emphasis was put on the quality of parentschildren relationship, families' life experiences and preventive health factors [17]. Baumrind [18], Dumas and Lafreniere [19] and Meisels and Shonkoff [20] argued that the dimensions and characteristics of the interaction that enhance the optimal child development include relationships reciprocity, parental emotional availability and scaffolding environment. To sum up, intervention programs were first developed within an educational perspective and gradually adopted a systemic, developmental perspective in order to combat children's developmental disabilities [11, 12].

\section{INCLUSIVE EARLY EDUCATIONAL INTERVENTION}

In the US, under the revision of Individuals with Disabilities Education Improvement Act (IDEIA) [21], schools are mandated to include at risk preschoolers with their typically developed counterparts. According to the educational inclusion rationale and the beliefs of professionals and families with children with disabilities, it is preferred that children with disabilities to be placed in inclusive settings because they will benefit more than to be placed in special school settings. Nevertheless, as Cavallaro, Haney and Campello argue [22], some accommodations should be made so that children's learning is not hindered from the ongoing developmentally appropriate curriculum.

The common aim of all early intervention programs is that at risk children should receive high quality special preschool education, like typically developed children, so that to become members of the kindergarten classroom by participating in classroom activities and develop positive social relationships with their peers and their teachers [23, 24].

According to Simeonnson [25] and Guralnick, [26] preschool special education was developed on the basis of providing education and support to young children and their families in order to minimize the effects of disability, risk or delay on the developmental benchmarks and learning outcomes. The decision over child's placement should be justified from both professionals and parents, who should be certain that the inclusion program is of high quality and that teachers are able to plan and implement individualized learning experiences according to child's needs [22].

The establishment of Response to Intervention (Rtl) after 1996 provided a multitiered provision model, which fostered the inclusion of preschool children. Rtl is a systematic process of decision making that enables the effective response to learning of children with learning difficulties and behavior problems [27]. RtI offers intensive teaching to children according to their needs and serves as an evaluation basis of effective educational practices and uses applied behavior analysis, diagnostic prescriptive teaching, curriculumbased measurement, and pre-referral intervention, according to all of which decisions can be made and the 'problem' of child's inclusion to be solved [27]. Rtl is common to current programs of prevention, early intervention and family support that prevent future school failure and developmental delay or disability [28].

Most of Rtl practices have focused on cognitive development and fewer on social behavior. Rtl puts emphasis on prevention and its implementation 
practices regarding cognitive growth and social behavior enabled the creation of tiered approaches, which followed the structure of public health systems The Rtl approach serves the cognitive and behavioral domains of children's development and puts emphasis on screening, on progress monitoring and on decision making in order to enable efficient interventions for children whose cognitive or social behavior do not respond to school curriculum [27]. Rtl is considered a challenge for early educational intervention since it provides a conceptual and theoretical preschool special education framework and acknowledges the importance of high quality preschool education programs.

\section{EFFECTIVE INCLUSIVE CURRICULA FOR EARLY INTERVENTION}

According to Wilks A, Nyland B, Chancellor B, et al. [29], current evidence-based preschool core curricula, which are mainly implemented in the US and Canada, aim at facilitating both children's socialization and education, given the importance of the first years of life for children's development is generally recognized. This presupposes that teachers should be highly trained so that to be able to support and implement effectively the curricula [30, 32]. The quality of a curriculum depends on the everyday experiences and learning opportunities offered to the child and is reflected on teacher-child relations, in peer relations, in child's learning and social activities and in teachers' work satisfaction level. It seems that at risk children's responsiveness to the curriculum is more sensitive and warm in small groups of children [31, 33]. Mainstream teachers' level of expertise may increase the quality of educational programs by enriching children's language, cognitive experiences and positive interactions with peers and adults [34].

Most of the preschool core inclusive curricula put emphasis on school readiness language and literacy skills development (e.g., phonological) and cognitive skills development (e.g., self-regulation, pre-maths and pre-science skills). Teaching children at risk those skills requires modifications on these skills with the use of methods such as role playing, exploration, behavior guidance with no teasing and punishment [35]. The framework of these intervention curricula minimizes the negative consequences of cognitive and social delay. These kinds of intervention curricula are also used within Rtl approaches.

\section{EARLY INTERVENTION IN EUROPE}

Early intervention in Europe was enhanced with the implementation of European projects, particularly 'Helios' (1988-1991), which aimed at improving knowledge on the education of preschool, primary and secondary school children with special educational needs among European countries [36]. Later on, Eurlyaid was founded (1993), a working party consisting of experts and representatives of parents' associations from various EC countries. Eurlyaid developed a provisional manifesto on early intervention for children with developmental disabilities, which described early intervention stages and procedures, delineated the target group of children whose needs should be addressed, applied an interdisciplinary approach, focused on families' needs and put emphasis on early education and training [1].

European Agency for Development in Special Needs Education summarized early childhood intervention practices in EU countries during 20032004 [37]. Summary revealed both diversity and commonalities of early childhood intervention principles and services in different EU countries. Diversity included differences in early intervention services time onset. Commonalities included common shared characteristics such as: 1. availability, which means that all children and families in need of support should be reached as early as possible in order to guarantee the provision of similar quality of services; 2 . proximity, meaning that support should be available as close as possible to families; 3 . affordability, which means that services are offered free of charge or at minimal cost to families; 4. interdisciplinary working, meaning that professionals who support young children and their families have diverse backgrounds and share and coordinate information; and 5 . diversity of services, which means that young children and their families should have access to health, social and preschool educational services [38].

After 2000 inclusive early educational intervention was implemented in Europe, mainly in the Netherlands, Germany and Belgium. In Spain and the UK there is less special provision whereas in Italy and Greece children with special educational needs are educated in mainstream schools. In some European countries disabled children are regarded as requiring special placement and education. In most of the European countries educational programs for preschoolers with severe disabilities aim at social and life skills development [38]. In many European countries 
inclusive education plans (IEPs) enable the adaptation and individualization of inclusive curricula. For the facilitation of inclusion services, support staff is used in most of the European countries. Contrary to the US, European research evidence regarding early intervention operation and benefits is limited [1, 39]. Also there are no available data on either the numbers of children and families that received early intervention services in relation to the general population of each country, or the type of intervention programs that were used.

\section{EARLY INTERVENTION IN GREECE}

Traditionally, in Greece early intervention services have been, and are still offered as remedial supports and treatments to children with disabilities from 0-4 years of age in various institutions according to the level of disability. The diagnosis for children's disabilities can also be made in child psychiatric hospital departments in which interdisciplinary assessment is available. After diagnosed, children are usually referred to private practitioners (speech therapists, ergo-therapists, psychologists, psychiatrists etc) for treatment according to their disabilities. Until 1984, special kindergartens were operating within these institutions, which provided mainly care and training for preschoolers with disabilities. Both institutions and special kindergartens were operating under the authority of Ministry of Health and Welfare. Currently, institutions with children of various disabilities (e.g. deaf, blind, intellectually disabled, autistic etc) offer special treatments that may be considered early intervention services for children starting from birth or three-years-old depending on when the disabilities are detected. After the 1143/1981 law enforcement [40], the education of disabled children and students of all school levels started to operate under the authority of the Ministry of Education. However, children's diagnosis continued to be available either in institutions or in diagnostic centers in Athens and Thessaloniki.

Greece has adopted and implemented the United Nations' declarations on equal opportunities and the European Union legislation about students' mainstreaming. The education of students with disabilities and special needs included preschool education. Law 2817/2000 [41], assigned the evaluation and support of at risk students and students with disabilities beyond 4 years of age to the Centers for Diagnosis, Evaluation, and Support (KDAY) under the authority of the Ministry of Education. Child psychiatric hospital departments continued to offer early intervention services for children from 0-4 years of age. Under this law, specialized professionals were appointed (e.g. speech-therapists, ergo-therapists etc.) to enable an interdisciplinary evaluation and to serve in special schools and kindergartens in order to support children and families. The institutions and child psychiatric diagnostic centers were operating under the authority of the Ministry of Health and Welfare. On the other hand KDAY were operating under the authority of the Ministry of Education. This situation created numerous problems. For example, children's progress could not be monitored over time, children's evaluations were not homogenous due to lack of coordination. Moreover, the multidisciplinary nature of treatments and the lack of a coordinating agency impeded the implementation of comprehensive early intervention.

The term 'early intervention' was officially introduced in Greece under the Law 3699/2008 enforcement [42], according to which early intervention was considered as support, medical care, therapeutic treatments and early educational intervention in accordance to child's diagnosis and parental agreement. The above Law provides for the operation of inclusive kindergartens and the use of individualized special support within mainstream kindergartens for handicapped children, mainly for those with cerebral palsy or severe behavior disabilities. The initial children' educational evaluation was supposed to be made by kindergarten teachers who should have differentiated classroom activities and tasks, and if some students could not 'respond' to these activities and tasks for a 'significant' amount of time, then these students were referred to diagnostic centers with parental consent.

As regards special education curricula, till 1996 there was no special curriculum for any of the education levels. With the presidential decree 301/1996, a framework for special education curriculum was legislated concerning primary school children and could used for preschool children, mainly as regards their social and adaptive skills.

Early intervention principles under the Eurlyaid and the EU concepts were transferred to Greece in 1996 with the publication of Eurlyaid manifesto in the journal 'Paidagogikh Epitheorish' (Educational Review), Greek Educational Association [43]. The teaching of early intervention principles and practices to undergraduate and postgraduate students of Preschool University 
Education Departments have developed gradually since then. In most of University Departments teaching was mostly theoretical and focused on the principles and policy of inclusion (e.g describing children with disabilities, highlighting family participation on intervention practices, analyzing mainstreaming policies etc.). Till now students from Preschool Education Departments do not receive any practical training in inclusive early education programs, nor do students in the Department of Special Needs Education, University of Thessaly. This might explain the limited research on early intervention in Greece, which deals mainly with teachers' opinions over early intervention [44, 45] or quality evaluations of early intervention programs [46] or experimental intervention programs [47, 48]. Preschool teachers' needs for special education training have been expanding. According to the records of Special Education Directorate in the Ministry of Education, currently in Greece there are 449 inclusion kindergartens with 999 children. 131 of them receive individualized support. There are also 110 special kindergartens within institutions and special schools, which address the needs of 447 children with severe disabilities.

\section{A GREEK PARADIGM OF EARLY INTERVENTION CURRICULUM}

For prospective preschool teachers' training in inclusion and early intervention educational practices, the School of Early Childhood Education, Special Needs Department, Aristotle University of Thessaloniki offers practical training in the design and implementation of an inclusive educational intervention program. The program initially started in 1996 with the implementation of an adapted kindergarten core curriculum, aimed at educating all kindergarten children. Cognitive and social activities were mostly used. Emphasis was put on children's cognitive strategies' training in mainstreaming kindergarten settings. Most of these children either had mild intellectual disabilities or were at risk for intellectual disabilities. Kindergarten curricula flexibility and developmental nature enabled the use of cognitive and meta-cognitive tasks. Moreover, cognitive training was applied to children with developmental disabilities and language impairments within small groups. Program outcomes were evaluated in 2004 [49].

The program was modified according to the current approaches to early intervention and inclusion. From 2004 onwards the program lasts one academic year and follows Rtl stages regarding kindergarten children
[27]. It is implemented in 25 inclusive kindergarten settings under the supervision of teaching staff members of the Special Educational Department, School of Early Childhood Education and early childhood education associates.

During the first stage, university students, together with the general and special classroom teacher, evaluate all children's progress in both cognitive and social domains in order to detect: children who respond adequately to appropriate developmentally tasks, children at risk for failure if they do not receive additional support, and children with established or already diagnosed disabilities. Children are assessed after systematic observation in the class made with screening tools that measure cognitive and language development as regards school readiness and with checklists measuring children's adaptability and social relations. The program is assessed at close and regular intervals during the academic year since its operation and children's progress is continuously assessed for possible disability signs in other children to be identified.

In the second stage, for children who were identified as non respondents, dynamic assessment is used in a form of mediated learning. Also these children are referred for interdisciplinary assessment to KDAY. Dynamic assessment was chosen because it is an evidence-based, interactive assessment procedure, usually applied in a test-teach-retest form. Dynamic assessment is also used with preschool children with diagnosed disabilities and at risk for disabilities and is considered to be an efficient tool for the design of specialized and individualized effective programs [50, 51]. Children are assessed on the selected tasks and trained in cognitive functioning skills and receive empirical knowledge.

The current dynamic assessment approaches that are used are based on Vygotsky's socio-cultural theory, as presented by Feuerstein in mediated learning framework [52] according to which, every child's function is noticeable first on a social level and later, via an internalized process, on the psychological level. The internalized process is gradually developing with support given from an experienced adult or peer [53]. This process enables development modifiability through interactions via direct acquisition of experiences, mediation of experiences, or mediation of experiences that require the participation of a person who process and interprets interaction experiences [54]. This process, called 'mediated learning 
experience' (MLE), is implemented in the intervention program. During dynamic assessment the mediator has to develop and maintain three interaction conditions: mediation of intentionality, mediation of meaning and mediation of transcendence. Interaction between the tasks and the child one hand and the dynamics of mediation on the other, are referred to as mediation of behavior regulation. The mediator uses tools and processes designed to facilitate maximum child progress. These tools and processes enable the evaluation of child's disabilities and the extent to which these disabilities may be remediated by mediated learning. Each MLE may improve cognitive functioning and show if there are any indications of developmental delay at each stage (input-elaboration-output).

Dynamic assessment is implemented by two university students in order to monitor more effectively children's progress, to exchange ideas about the selection of children's tasks and modify the mediation procedure where necessary, in cooperation with the supervisors. Dynamic assessment is used for two months till university students and the supervisors realize the modification of certain child learning behaviors.

After the completion of the dynamic assessment evaluation at the end of the first academic semester and the interdisciplinary children's assessment (e.g., child's medical condition, socio cultural characteristics, emotional and behavioral functioning), in the third stage of the RTI evidence-based decisions are made, which take into account child's responsiveness to core curriculum aims. The implementation of the core curriculum during the practical training is based on empirical-experiential learning and the thematic approach, puts emphasis on emergent literacy, school readiness and socialization and aims at the child's comprehensive development. The selected themes and tasks that are used emerge through child-teacher cooperation. The daily program includes a large group activity for all children, a small group specialized activity for non-responding children and an individualized activity for children with disabilities. The program adaptation involves the theme and the tasks to be used. Topic and tasks selection is made so as to enable the minimum participation of children with special education needs in the core curriculum during the large group activity.

In the fourth stage modifications are made within the specialized and the individualized programs. Specialized program tasks emerge from the core curriculum theme. Depending on children's disabilities, direct or indirect teaching of learning strategies along with programs of ability development are used. The specialized program includes tasks that focus on the child's disabilities. Specialized and individualized programs are implemented on the basis of the children's disabilities. What is mostly used for children with mild disabilities, is a school readiness program which focuses on oral and written language and literacy skills development. Specialized and individualized programs for children with severe disabilities focus on social interaction and self-regulation skills development. Most often there are two groups of children in the specialized program, of 1-2 children with disabilities. In the mild disabilities group, children with difficulties in school readiness without disabilities are also included. These children usually come from disadvantaged and/or language and culturally divergent environments. In the severe disabilities group, children with behavior difficulties due to family and social disadvantaged conditions are also included.

Apart from the 2 university students, the general classroom teacher and the special needs teacher also participate in the curriculum daily program, and all of them evaluate the tasks and activities and make any necessary modifications. The regular and the special classroom teacher cooperate with the members of the teaching staff of the Special Needs Department of the School of Early Childhood Education for the practical training follow up and the monitoring of children's progress. Core curriculum, specialized and individualized programs are evaluated every week and university students receive feedback for program improvements and changes in teaching approaches or tasks, if necessary. University students also make use of intervals in order to organize group play activities aiming at peer relations development among children with and without disabilities. These activities are also helpful for children at risk for exclusion due to disadvantaged social conditions.

\section{AN EXAMPLE OF EARLY INTERVENTION INCLUSION PROGRAM IMPLEMENTATION}

In a kindergarten classroom of western Thessaloniki, which is considered a disadvantaged area, there are 20 children, 5 to 6 years old. The classroom teacher and the special education teacher detected more than half of the children as being at risk for disabilities. None of these children was diagnosed for a disability. In the detected group there were 9 culturally and linguistically diverse (two Albanian, five 
Pontian Greeks from the former Soviet Union, and two Roma origin children). The systematic assessmentscreening of the detected children showed that 8 of them had special education needs. These children received dynamic assessment with mediated learning experiences.

More specifically, undergraduate students as facilitators assessed all children over various tasks. One task included narrative story-telling and story grammar problems with the use of pictures of progressive difficulty as probes: using modeling methods, undergraduate students facilitated the children to put the pictures in order and retell the story. Another task included phoneme-grapheme correspondence: first, the facilitators showed a picture of four graphemes to each child, 2 of which were acoustically similar, and then they pronounced one of these phonemes, so that the child would recognize the grapheme from the picture. Besides, tasks of acoustically similar words were used. Finally, in order to assess children's peer relations, children participated in motor skills play activities in small groups where they were encouraged to socially positive behaviors, such as touch each other hands.

Results from dynamic assessment and various information reported by the diagnostic centers, enabled the identification of 2 of the detected children as severe disabled. These children could not communicate verbally, had behavior and visual-sensory disabilities, and refused to interact with their peers. During the progress monitoring stage, dynamic assessment compensated the disabilities of another 2 detected children. These children were of Albanian origin, which could account for their low language competence, due mainly to their bilingualism. The remaining 4 children had mild disabilities, mainly in phonological awareness, story-telling and spatial-temporal processing. One of these children was a Roma child and the other 3 were Pontian-Greeks from the former Soviet Union. Core curriculum adaptations were implemented in the thematic units and the tasks assigned to kindergarten children experiencing disabilities so that all children could participate in the school activities, even at minimum level. For example, one thematic unit that was selected was 'my neighborhood'. The constructivist approach was retained and undergraduate students' mediating role was enhanced since dynamic assessment evaluation proved that their role was useful for children with disabilities.

A strategies training program about a sub-theme called 'a story from my home' was implemented in the specialized program, in which the same thematic core curriculum thematic unit was also retained. The two bilingual children with language difficulties participated in this program. The selected strategy chosen in the specialized program was story grammar with picture probing. Undergraduate facilitators explained to children that they had to create their own story on a topic about their home (e.g. 'my toys') using pictures or other objects. They also encouraged children to express their emotions and tell their story in a consistent and coherent way using the most suitable words. In cases in which children were mainly describing and not 'telling' their story, undergraduate facilitators or children peers acted as mediators. Other tasks used included phonological activities with words discrimination, analysis, synthesis and morphemegrapheme correspondence and alphabetic principle activities. Children with severe disabilities that could not respond to the above activities had to draw the letters with the support of their peers. Additional tasks that were used included spatial-temporal activities, where children were asked to indicate what happened in the story and what might occur afterwards.

After the completion of the specialized program, which lasted one teaching hour, children without disabilities and children with mild disabilities started reengaging into the core curriculum activities. Children with severe disabilities participated in an intensive individualized program. This program included experiential activities on discrimination, correspondence and analogy as well as social activities (e.g., 'getting to know our neighborhood', 'visiting the grocery store'), which were included in the same thematic unit used in the core and specialized program.

During intervals, the classroom teachers and the undergraduate facilitators organized common motor skills and play activities in order to support children's social inclusion.

Classroom participation and progress of each child was recorded in the child's portfolio. Moreover, at the end of the program all children were evaluated in terms of their response to intervention.

\section{CONCLUDING REMARKS}

To sum up, in undergraduate students' practical training in the School of Early Childhood Education, Special Needs Department, Aristotle University of Thessaloniki, an inclusive early education program was implemented. This program was based on response to intervention, as implemented in kindergartens. For 
children's progress monitoring, dynamic assessment with mediated learning experiences was mainly used. In the specialized program, strategies' training for children's school readiness was used. In the individualized program, activities for the development of children's cognitive abilities and socialization were used. Even though the classroom teachers and the undergraduate facilitators perceived positively the results of the inclusion intervention program in children, there are no evidence based evaluation of the results. Nevertheless, it should be noted that the intervention program is under the process of evaluation.

There is also no evidence whatsoever regarding children's progress in the primary school. This is mainly due to lack of continuity between kindergarten and primary school education in Greece at all levels (policy, curricula, teaching methods etc.). One indicator of such a positive outcome is documented in an ongoing $\mathrm{PhD}$ research conducted in the School of Early Childhood Education, Special Needs Department, Aristotle University of Thessaloniki. The primary impeding factor in a longitudinal analysis of children's development, is that children's portfolia are not used in Greek primary and secondary school education. In addition, the schools participating in the intervention program targeting inclusion are not representative of the Greek educational reality. For more than 20 years these schools have been adapting the specific inclusion philosophy of the Special Needs Department of the School of Early Childhood Education, Aristotle University of Thessaloniki. Consequently, school practices have been influenced by this specific approach. Finally, it is worth mentioning that neither any available official inclusive curricula nor any official screening tools are used in order to assess children, especially at risk children.

\section{REFERENCES}

[1] De Moor JMH, Van Waesberghe BTM, Hosman JBL, et al. Early intervention for children with developmental disabilities: manifesto of the Eurlyaid working party. Int $J$ Rehabil Res 1993; 16(1): 23-32. http://dx.doi.org/10.1097/00004356-199303000-00003

[2] Early Childhood Learning and Knowledge Center, ECLKC [homepage on the internet] [cited 2015 Nov 10] Available from: https://eclkc.ohs.acf.hhs.gov/hslc

[3] Wolery M, Doyle PM, Gast DL, et al. Comparison of progressive time delay and transition-based teaching with preschoolers who have developmental delay. J Early Interv 1993; 17(2): 160-176. http://dx.doi.org/10.1177/105381519301700207

[4] McDonnell AP, Brownell KL, Wolery M. Teaching experience and specialist support: A survey of preschool teachers employed in programs accredited by NAEYC. Top Early Childh Sp Ed 1997; 17(3): 263-285.

http://dx.doi.org/10.1177/027112149701700303
Buscemi L, Bennett T, Thomas D, et al. Head Start: Challenges and training needs. J Early Interv 1996; 20(1): 1-13. http://dx.doi.org/10.1177/105381519602000101

[6] Barnett DW, Carey KT, Hall JD. Naturalistic Intervention Design for Young Children Foundations, Rationales, and Strategies. Top Ear Childh Sp Ed 1993; 13(4): 430-444. http://dx.doi.org/10.1177/027112149301300407

Olness KMD. Effects on brain development leading to cognitive impairment: a worldwide epidemic. J Dev Behav Pediatr 2003; 24(2): 85-137. http://dx.doi.org/10.1097/00004703-200304000-00009

[8] Park J, Turnbull AP, Turnbull III HR. Impacts of poverty on quality of life in families of children with disabilities. Except Children 2002; 68(2): 151-170.

[9] Burchinal MR, Robertsc JE, Hooper R, et al. Cumulative risk and early cognitive development: A comparison of statistical risk models. Dev Psychol 2000; 36(6): 793-807.

http://dx.doi.org/10.1037/0012-1649.36.6.793

[10] The Education of the Handicapped Act Amendments of 1986; P.L. 99-457.

[11] Guralnick MJ. Inclusion as a core principle in the early intervention system. In: Guralnick MJ, Ed. The developmental systems approach to early intervention. Baltimore: Brookes 2005; pp. 59-69.

[12] Guralnick MJ. An overview of the developmental systems model for early intervention. In: Guralnick MJ editor. The developmental systems approach to early intervention. Baltimore: Brookes 2005; pp. 3-28.

[13] Guralnick MJ. Efficacy research in early childhood intervention programs. In: Odom SL, Karnes MB, Eds. Early intervention for infants and children with bandicaps: An empirical base. Baltimore: Brookes 1988; pp. 75-88.

[14] Shonkoff JP, Hauser-Cram P. Early Intervention for Disabled Infants and Their Families: A Quantitative Analysis. J Am Acad Pediatr 1987; 80(5): 650-658.

[15] Bryant $D$, Maxwell $K$. The effectiveness of early intervention for disadvantaged children. In: Guralnick M, Ed. The effectiveness of early intervention. Baltimore: Brookes 1997; pp. 23-46.

[16] Martin SL, Ramey CT, Ramey S. The prevention of intellectual impairment in children of impoverished families: findings of a randomized trial of educational day care. Am J Public Health 1990; 80(7): 844-847. http://dx.doi.org/10.2105/AJPH.80.7.844

[17] Guralnick MJ. Why early intervention works: A systems perspective. Infants and Young Children 2011; 24: 6-28. http://dx.doi.org/10.1097/IYC.0b013e3182002cfe

[18] Baumrind D. The average expectable environment is not good enough: a response to Scarr. Child Dev 1993; 64(5): 1299-1317.

http://dx.doi.org/10.2307/1131536

[19] Dumas JE, LaFreniere PJ. Mother-child relationships as sources of support or stress: a comparison of competent, average, aggressive, and anxious dyads. Child Dev 1993; 64(6): 1732-1754.

http://dx.doi.org/10.2307/1131466

[20] Meisels SJ, Shonkoff JP. Early childhood intervention: A continuing evolution. In: Shonkoff J, Meisels SJ, Eds. Handbook of early childhood intervention. New York: Cambridge University Press 2000; pp. 3-31. http://dx.doi.org/10.1017/CBO9780511529320.003

[21] IDEIA. Individuals with disabilities education improvement act. Pub. L. No. 108-446, 118 Stat. 2647. 2004

[22] Cavallaro CC, Haney M, Cabello B. Developmentally appropriate strategies for promoting full participation in early childhood settings. Top Early Child Spec 1993; 13(3): 293307.

http://dx.doi.org/10.1177/027112149301300307 
[23] Bailey DB, McWillam RA, Buysse V, et al. Inclusion in the context of competing values in early childhood education. Early Child Res Q 1998; 13(1): 27-47. http://dx.doi.org/10.1016/S0885-2006(99)80024-6

[24] Guralnick MJ. The Nature and meaning of social integration for young children with mild developmental delays in inclusive settings. J Early Interv 1999; 22(1): 70-86. http://dx.doi.org/10.1177/105381519902200107

[25] Simeonsson RJ. Risk, resilience \& prevention: promoting the well-being of all children. Baltimore: Paul H Brookes Pub Co; 1994.

[26] Guralnick MJ. Early Intervention for children with Intellectual Disabilities: Current Knowledge and Future Prospects. J Appl Res Intellect 2005c; 18(4): 313-324. http://dx.doi.org/10.1111/j.1468-3148.2005.00270.x

[27] Sugai G. Responsiveness-to-intervention: lessons being learned. Keynote presentation at the U.S. Department of Education RTI Summit, Washington, D.C. 2007.

[28] VanDerHeyden AM, Snyder P. Integrating frameworks from early childhood intervention and school psychology to accelerate growth for all young children. School Psychol Rev 2006; 35(4): 519-534.

[29] Wilks A, Nyland B, Chancellor B, et al. Analysis of curriculum/learning frameworks for the early years (birth to age 8). East Melbourne: Victorian Curriculum and Assessment Authority 2008.

[30] Ackerman DJ, Sansanelli RA. The source of child care centre preschool learning and program standards: implications for potential early learning challenge fund grantees. Early Child Res Prac 2010; 12(1).

[31] Gerber S, Scott L. Designing a learning curriculum and technology's role in it. Educ Tech Res Dev 2007; 55(5): 461-478. http://dx.doi.org/10.1007/s11423-006-9005-6

[32] Harrison LJ, Ungerer JA, Smith GJ, et al. Child care and early education in Australia: the longitudinal study of Australian children. Social policy research paper no. 40. Canberra: Department of Families, Housing, Community Services and Indigenous Affairs 2009.

[33] Pungello EP, Kainz K, Burchinal M, et al. Early educational intervention, early cumulative risk, and the early home environment as predictors of young adult outcomes within a high-risk sample. Child Dev 2010; 81(1): 410-426. http://dx.doi.org/10.1111/j.1467-8624.2009.01403.x

[34] Effects of Preschool Curriculum Programs on School Readiness. PreSchool Curriculum Evaluation Research Consortium. US Department of Education 2008.

[35] Fox L, Dunlap G, Hemmeter M, et al. The teaching pyramid: a Mmodel for supporting social competence and preventing challenging behavior in young children. Young Children 2003; 58(4): 48-52.

[36] HELIOS "Handicapped people in the European Community living independently in an open society". The Commission of European Communities. (1988/1991; followed by HELIOS II, 1992/95)

[37] European Agency for Development in Special Needs Education. Early childhood intervention analysis of situations in Europe. Key aspects and recommendations. Brussels. 2005.

[38] NESSE network of experts: education and disability/special needs. Policies and practices in education, training and employment for students with disabilities and special educational needs in the EU, Independent Report for the European Commission 2012.

[39] Carpenter B. Early childhood intervention: possibilities and prospects for professionals, families and children. British $\mathrm{J}$ Special Educ 2005; 32(4): 176-183.

http://dx.doi.org/10.1111/j.1467-8578.2005.00394.x

[40] Law 1143/1981. Greek Government. 80 -A- 31.3.1981 (in Greek).

[41] Law 2817/2000. Greek Govermenent. 78 -A- 14.3.2000 (in Greek).

[42] Law 3699/2008. Greek Government. 199 -A- 2.10.2008 (in Greek).

[43] De Moor JMH, van Walsberghe BTM, Tzouriadou M, Kontopoulou M. Early intervention in children with developmental disabilities. A manifesto of the Eurlyaid working group. Educational Review 1996; 023:16. (in Greek).

[44] Fyssa A, Vlachou A, Avramidis E. Early childhood teachers understandings of inclusive education and associated practices: reflections from Greece. International Journal of Early Years Education 2014; 22(2): 223-237. http://dx.doi.org/10.1080/09669760.2014.909309

[45] Zoniou-Sideri A, Vlachou A. Greek teachers' belief systems about disability and inclusive education. International Journal of Inclusive Education 2006; 10(4-5): 379-394. http://dx.doi.org/10.1080/13603110500430690

[46] Fyssa A, Vlachou A. Assessment of quality for inclusive programs in Greek preschool classrooms. Journal of Early Intervention 2015; 37(3): 190-207. http://dx.doi.org/10.1177/1053815115606908

[47] Nanou A. A psychoeducational strategy training program for the improvement of story telling in preschool children with developmental language disorders. PhD Thesis. Aristotle University of Thessaloniki 2004 (in Greek).

[48] Anagnostopoulou E. Cognitive and language disabilities of preschool children at risk to develop school difficulties: a psycho-pedagogical program of early intervention with the use of analytic methods. PhD Thesis. Aristotle University of Thessaloniki 2004 (in Greek).

[49] Manavopoulos K. A pilot study of an early intervention educational program in Greece. Paper presented in the European Association for Mental Health in Mental Retardation (EAMHM) Congress 'Mental health and mental retardation: a lifespan multidisciplinary approach', Rome, Italy, September 17-20, 2003.

[50] Lidz CS. Practitioners 's guide to dynamic assessment. New York: The Guilford Press 1991.

[51] Miller L, Gillam R, Pena E. Dynamic assessment and intervention: Improving children's narrative abilities. Austin: PRO-ED 2001.

[52] Feuerstein R. The dynamic assessment of retarded performers: The learning potential assessment device, theory, instruments, and techniques. Baltimore: University Park Press 1979.

[53] Tzuriel D. Dynamic assessment of young children: educational and intervention perspectives. Educ Psychol Rev 2000; 12(4): 385-435.

http://dx.doi.org/10.1023/A:1009032414088

[54] Feuerstein R, Falik LH. Learning to think, thinking to learn: a comparative analysis of three approaches to instruction. $\mathrm{J}$ Cognitive Educ Psychol 2010; 8(1): 4-20. http://dx.doi.org/10.1891/1945-8959.9.1.4 